\title{
Estimation of aflatoxin production in the seeds of Beta vulgaris var. Cicla, Amaranthus tricolor and Portulaca oleracea at different relative humidity levels during storage
}

\author{
GANGAPURAM SETHUMADHAVA RAO, AMBALLA HINDUMATHI* AND BHIMANATHINI \\ BHADRAIAH
}

Department of Botany, Osmania University, HYDERABAD (TELANGANA) INDIA(Email : hindumathidr@ yahoo.com)

\begin{abstract}
The experiment was conducted to study the effect of relative humidity and moisture content on seed germination and aflatoxin production of three vegetable seeds during storage. Six Aspergillus flavus strains were isolated from the three leafy vegetable seeds and screened for aflatoxin production. The evaluation of toxigenic potential of the isolates showed that 73.33 per cent of the A. flavus strains isolated from the seeds of three different leafy vegetables collected from Mbnr and RR districts presented a toxigenic potential. Among the $A$. flavus 66.67 per cent isolates were producers of aflatoxin $B_{1}$ and 33.33 per cent of the isolates produced aflatoxin $G_{1}$. Aflatoxin $B_{1}$ was detected in the A. flavus treated seeds of Bv and At collected from both Mbnr and RR dist. While, aflatoxin $\mathrm{G}_{1}$ was detected only in Bv samples of Mbnr and RR dist. The results showed that the storage period of vegetable seeds is a critical phase, as indicated by the high percentage of aflatoxigenic isolates.
\end{abstract}

Key Words : Aflatoxin, Aspergillus flavus, Relative humidity, Seed germination

View Point Article : Rao, Gangapuram Sethumadhava, Hindumathi, Amballa and Bhadraiah, Bhimanathini (2015). Estimation of aflatoxin production in the seeds of Beta vulgaris var. Cicla, Amaranthus tricolor and Portulaca oleracea at different relative humidity levels during storage. Internat. J. agric. Sci., 11 (1): 7-12.

Article History : Received : 28.09.2014; Revised : 17.10.2014; Accepted : 03.11 .2014

\footnotetext{
* Author for correspondence
} 